\title{
Study on the Utilization of Group Discourse Power in Business Model in All-Media Era
}

\author{
$\mathrm{Xu}$ Jie \\ Dept. of Commercial \& Management \\ Zhejiang Business Vocational College \\ Hangzhou, China \\ 65166756@qq.com
}

\begin{abstract}
With the increasing discourse power of net groups in all-media era, business model has gone through a series of changes. By analyzing successful cases of Chinese internet companies and concluding their business model, this essay concentrates on the relationship between discourse power and business model in commercial field, explores four stages in the utilization of group discourse power: beginning stage "group discourse competition", developmental stage "construction of group discourse power", middle stage "satisfy discourse group needs", late stage "expand discourse group". On the basis of these stages, it illustrates a way in the future new business model.
\end{abstract}

Keywords—discourse power, group, business model, stage

\section{Discourse Power In All-Media ERA}

Ever since Z.Harris put forward the concept of "Discourse Analysis", discourse, along with discourse power, has gradually become a hot topic. Michel Foucault defined discourse as a specific speech way closely associated with social power, a form more complex than language and speech. In this process, discourse has two properties, discourse power and discourse right.[1] In a situated context, there always exists discourse competition, people or groups from different classes use various discourse strategies to consolidate or resist social power. Therefore, the concept of discourse power not only includes the right to express and to influence, but also the social environment and mechanism as well.

Traditionally, discourse power has already claimed its position in politic, culture and media fields. The advantaged in these fields normally has a strong power in strengthening their discourse and leading the disadvantaged. However, things have changed with the coming of all-media era. The continuously updated information and extending transformation channel have helped China enter into a stage of discourse power redistribution. In this era, Internet and various new-media apps enable a level playing field for all participants, where the disadvantage finds their chance to express the depressed interest demand. Discourse power competition between the advantaged and disadvantage, which is scarcely seen in the real world, appeared among "internet events" like "Fuwocheng (push-up)" in 2008 or "Duomaomao (hide and seek)" in 2009. In these events, people in real world having no power turned to express their doubts or anger on the net, conglomerating a great discourse power within internet context, forcing government re-investigate the cases. During these processes, netizens

This work was supported by the Planning Routine Program of Hangzhou Social-Science Organization, namely "The Research of Discourse Power Battle in Business Model under All-Media Era" granted Z16JC055. discovered their discourse power in implementing transparent supervision, maintaining traditional morality, preserving law justice and promoting social progress. Thereafter, internet discourse power is consciously strengthened. With following series occasional cases, it finally attracts numerous attentions from business field.

\section{Group Discourse AND Business Model INNOVATION}

In the marketing, there's an important theory named $4 \mathrm{P}$ Theory put forward by E.Jerome McCarthy in 1960. The flow of time has changed $4 \mathrm{P}$ to $4 \mathrm{C}, 4 \mathrm{R}$, until the $4 \mathrm{I}$ in this all-media era. The shift from 4P's "Product" "Price" "Promotion" and "Place" to 4I's "Interesting" "Interests" "Interaction" and "Individuality" is an obvious change of focus from "product" to "human". 4I Theory regards marketing relationship as the core, emphases on resource allocation, and gives attention to people demands, which in time meets the business needs in this era.

Traditional business model focuses on product to create value, uses celebrities, stars or professional experts in their promotion, and expects high discourse power functioning in the retail. But all-media era lowers this power; instead, it lifts the discourse power of normal people. Seen from Fig.1, different from the traditional travelling channel, the interpersonal circle helps product information transmitting more quickly, more effectively and more cheaply.

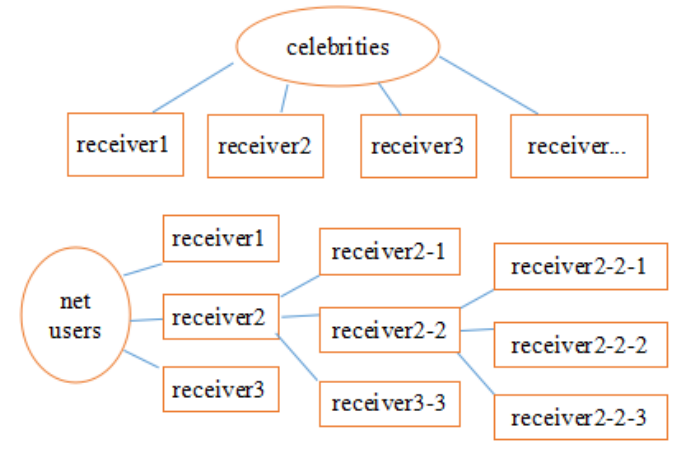

Fig. 1. Difference in the traditional and all-media era information channel

Under this circumstance, for companies, especially those internet companies, it makes good business sense to develop the capability to innovate business models. R. Amit and C. Zott (2012) defined a company's business model as a system of 
interconnected and interdependent activities determining the way the company "does business" with its customers, partners and vendors. The innovation can occur in 3 ways: by adding novel activities, by linking activities in novel ways, or by changing one or more parties that perform any of the activities. [2] M. Pynnönen, J. Hallikas and P. Ritala (2012) analyzed a innovation case, calling it "customer-driven business model", arguing customer needs adjust the marketing management. [3]

Companies embrace customer discourse power as a opportunity, since it plays two initial functions:

1) Grouping: in the net, voice of an individual is low, but forming a group will turn things into opposite. Therefore, grouping becomes an effective mechanism in forming society. Gustave Le Bon claims crowd psychology characters in "impulsiveness, irritability, incapacity to reason, the absence of judgment of the critical spirit, the exaggeration of sentiments".[4][5] These characteristics is of great advantage in the utilization of discourse power.

2) Linking: Social platforms such as WeChat, Weibo net people in a wider range of social channels. In these platforms, discourse of "people" has a more impressive impact both in strength and in scale. Elements in $4 \mathrm{P}$ are forced to change: "place" submits to "platform", "price" submits to "praise", and the value of "promotion" lies in the sharing numbers and "like" links rather than profits.

\section{Four Stages In UTILIZING GROUP DISCOURSE POWER}

"Grouping" and "Liking" compose two main functions applied to the business model innovation, embracing willingness to discourse power. With the discovering of importance and the attempting of utilization in group discourse power, business model innovation has gone through the following four stages:

\section{A. Beginning: Group Discourse Power Competition}

The beginning stage can be described as a kind of exploration. It appeared as internet phenomenon, recognized, noted and valued in commercial field, and finally being utilized as a strategy.

In 2014, QvodPlayer was prohibited for sharing the pirated and pornographic videos, and its CEO Wang Xinwas arrested. In the trial record released in 2016, LeTV was found to be the whistle-blower. It was a flash point of the whole event. Netuser groups entered into an "anti-LeTV" carnival, aimed to fight for the pitiful QvodPlayer. LeTV Baidu postbar was "exploded" by the overwhelming posts. Weibo of its CEO Jia Yueting was filled with "Give Back my Qvod". At that time, LeTV became a platform of a great war, the war between governmental policy to forbid the obscene and pornographic videos and netizen's right to watch it. Through the discourse of reproving Letv, these right-deprived netizens unconsciously form a group to express their suppressed interest. However, a "miserable target" as LeTV seemed to be, it in fact gained great fame in this war. According to Website global ranking data provided by ALEXA,the ranking of LeTV in the first half year of 2016 is as below:

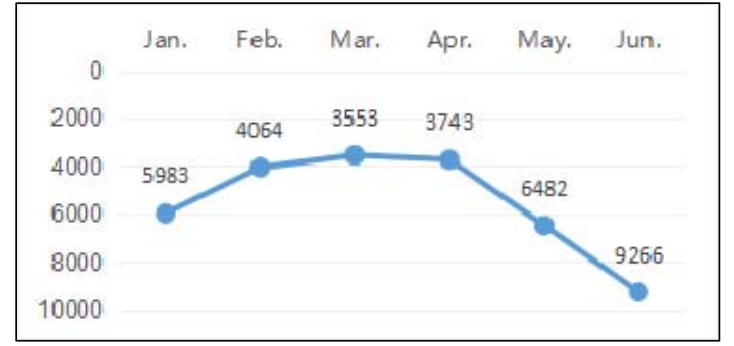

Fig. 2. Ranking of LeTV in the first half year of 2016

As can see in Fig.2, after the event, the ranking of LeTV global-wide increased sharply from 5983 to 3743 , more than 2000 place globally. Regretfully, LeTV didn't take this good chance to boost itself, ranking decreased three months later, and now it ranks behind 10000 .

Discourse power competition was found in those cases, and its function in publicity was discovered. Meanwhile, it was shown in the commercial field that publicity plus good reputation can bring directly the profit. In 2015, thanks to the "discourse right marketing", the movie "Monkey King: Hero is Back" reached nearly 1 billion, the highest movie box office result in Chinese cartoon history. It was far beyond market expectation. Various articles and essays were written to explore reasons. At that time, it was confront with movies acted by stars, written by celebrities or directed by famous host, but with its good reputation, thousands of netizens spontaneous advertised it to against the "idol-dominated" movie market. They regard themselves as safeguard of the "domestic conscience". This competition creates highly-evaluated topic and social positive feedback, attracting people joining in the group and entering into the cinema. The following cartoons, like "Big Fish \& Begonia" "Black Peanuts" try to copy this pattern, unluckily they do not meet such strong enemies and can not rise such hot topic.

Group discourse competition brings hot words like "stealing spotlight", and draw attention in the group discourse power. But the beginning stage has its own limitation---it relies on spontaneous act, and needs perfect timing and grouping. To remedy this limitation, another model comes out, and brings a new focus, community.

\section{B. Developmental Stage:The Construction of Group Discourse Power}

The developmental stage is to change discourse power utilization from passively to initially. It is a comprehensive display of 4I theory:

- Interesting: consistent with group fun

- Interests: meeting group interests

- Interaction: achieving group interaction in the community

- Individuality: satisfying individual needs

The process of obtaining discourse power in all-media era is divided into three steps: understanding, convincing and receiving. If the beginning stage lies in the spontaneous organization of netizens, group "following" and "inciting", then 
in the development model, the discourse right lies in conscious guidance of managers. Groups will understand the gap between the dominated and the normal, voluntarily be guided, give power to the holder, receive and accept all the discourse in community context. The modes can be concluded as the following Fig. 3:

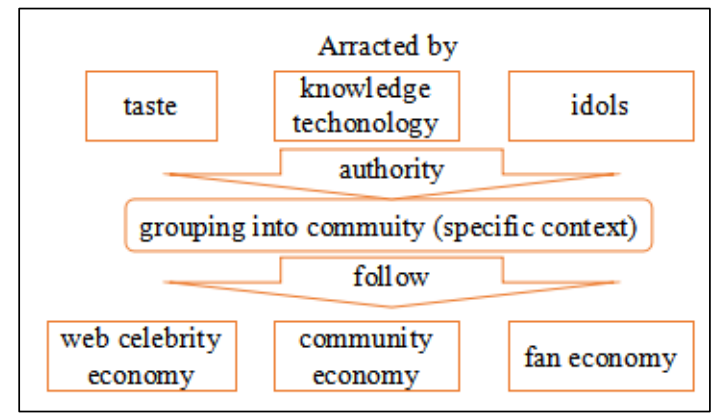

Fig. 3. Three kinds in the construction of discourse power

There are several modes appeared in this stage, and all achieve great success:

\section{1) Web celebrity economy}

Mostly refers to fashion icons, and usually dominated by girls with good taste. In this mode, they use social media to gather popularity, accumulate huge fans, promote targeted marketing, and convert fans to purchasing power. Web celebrities mostly arise from Taobao, and then penetrate into weibo youku etc. But with the development of We Media, funny icons enter into this camp. Papi, a short-movie marker from Youku, once made her name an estimated value up to 0.3 billion RMB.

\section{2) Socialnomics}

Different from the common net group, community refers to the organization of users with similar interests or values. This mode relies on knowledge and emphasize on the trust. Famous brands like "Luo's Logical Thinking (Luoji Siwei)", MIUI follow this mode. With the supply of knowledge or technology, rapid accumulation of audience, and the construction of community platform, they hold discourse power in the community in a short time. The increase in number of fans provides positive values in brand value. In 2017, number of fans subscribing Wechat account "Luo's Logical Thinking" climbs to 100 billion, boosting an estimated brand value to 1.32 billion in financing.

\section{3) Fan economy}

Usually associated with celebrities, idols and industry celebrities, fan economy depends on the enthusiasm from fans. Different from the above two modes, this mode creates economic and social value by the relationship between fans and those being fanned. This mode is normally seen in the cultural industry. In recent years, various IP TV programs, movies with idols have drawn great interest in this industry for the astonishing ability in earning profit. However, after years of disappointing, this kind of mode nowadays usually goes with the competition of discourse power.

\section{Middle Stage: Satisfy the Discourse Group Needs}

If the beginning and developmental model is to construct group discourse power, its further stages, be it middle or late model, concern with re-utilization of the discourse power. They begin with accumulated power, reuse it, with the following and trust from big discourse group, recreate brand power and reshape its company value.

Middle stage is about satisfying the discourse group, and its patterns include:

\section{1) Product chain expansion}

MIUI, for example, has expanded its product chain after gaining great success and large number of fans in mobile phone industry. By operating hunger marketing strategy, its CEO, Lei Jun, successfully shaped MIMU as a representative in costeffective products. Thereafter, MIMU no longer confined itself to the field of mobile phones. In 2014, it began to build its product chain. In 2015, eco-chain products revenue increased by $220 \%$. At the end of 2016 , Lei Jun publicly claimed that the annual income of the eco-chain was expected to reach 15 billion RMB. Up to March 2017, millet invested a total of 77 intelligent hardware companies, among which 16 have an annual revenue over millions, 3 over 1 billion, 4 become unicorns worth more than 1 billion USD.

In the concept of investment, two points are highly evaluated: the product must be highly concerned, easily iterated and tended to be "fanned". Meanwhile, it should be related to be main discourse group, 150 million fans with 18-35-year-old polytechnic male in the majority. Therefore, the construction of product chain is dependent on the existence of groups and the discourse power.

\section{2) New channels emergency}

Here new channels mainly refer to $\mathrm{O} 2 \mathrm{O}$, i.e. Online to Offline. According to "2017 China Local Living O2O Industry Research Report" issued by the third-party "Iresearch Institution" on July 11, 2017, the overall market of $\mathrm{O} 2 \mathrm{O}$ industry has exceeded 700 billion, lasting $40 \%$ of the high growth. It is expected that this market will reach 100 million in 2017 alone. [6]

With the rapid growth of local demand for the market, more and more Internet companies joined in this market, using their discourse power within the industry to expand the market. Dazhong Dainping, for example, originated from restaurant comment, entered this field in 2015 with its partner Meituan in take-away business. The road is not too tough for them to change from online to offline---by concentrating on the big amount of web-users, constantly recommending its take-away business; Meituan now occupies nearly half of the take-away industry.

\section{Late Stage: Expand the Discourse Group}

The middle stage depends on the existing discourse group and creates value through product and channels, the late stage do not limit itself to the group.

Alibaba, together with its eco-chain Taobao, Alipay and Ant Financial, can be seen as the forerunner of this model. This company always stands in the tide of innovation, willing to 
open up new scope and establish greater discourse in the larger context.

Alipay's development stage can be a vivid illustration. As the world's leading independent third-party payment platform, Alipay has already taken the absolute discourse power in online payment. But the coming of Wechat payment gradually become a threat to Alipay's position. On one hand, Alipay made full use of new technology, making Alipay more easy to use. On the other hand, it actively expands its eco-chain, explores the needs of the discourse group, and presented new functions like "Yu'e'bao". But the advantage of Wechat lies in its discourse power in social life and the accumulation of group user.

To win this battle, Alipay has to jump out from its rich country, create a bigger and greater empire. In 2015, Alibaba's 1212 festival went from Taobao online to offline. It changes strategy of 1111 Tmall and 1212 common E-shop to 1111 online and 1212 offline. This strategy creates great echo. At that day, Alipay's user groups are no longer limited to the young and fashion people. Irresistible to the temptation of $50 \%$ off, lots of old people who rarely use smart phones asked their kids to download Alipay, and rushed to do shopping. Later, Alipay pushed forward "national store program", and quickly entered into convenience stores, fruit shops, restaurants, and even corner stores.

Today, Alipay is not only an on-line pay tool, but also a "national liquidity mean". It enters Chinese daily life, constructs its discourse power within national context. In Hangzhou for example, people can live the whole day with no cash but a smart phone loaded Alipay.

In 2017, Ma put forward the concept of "new retail", willing to take Alibaba from Taobao's online superpower buying platform to offline supermarket mode. His attempt is a typical late stage model. This model is mostly taken by large companies, accompanied with strategy transition. This is a fusion model, usually goes after the maturity of middle stage. When a company wants to go further, it has to push itself to a far distance, and wins new groups to create new value by changing from "online" to "offline", "network group" to "entity group", which enlightens the future business model.

\section{CONCLUSION}

Group discourse shows its power not only in social, cultural and political field, but in economic filed as well. The reason why business models in this era attach more and more importance to it lies in the creation of value. Concluding from above stages, be it in the beginning, developmental, middle or late stage, group discourse creates, connects, attracts value. The development of four stages is shown blow:

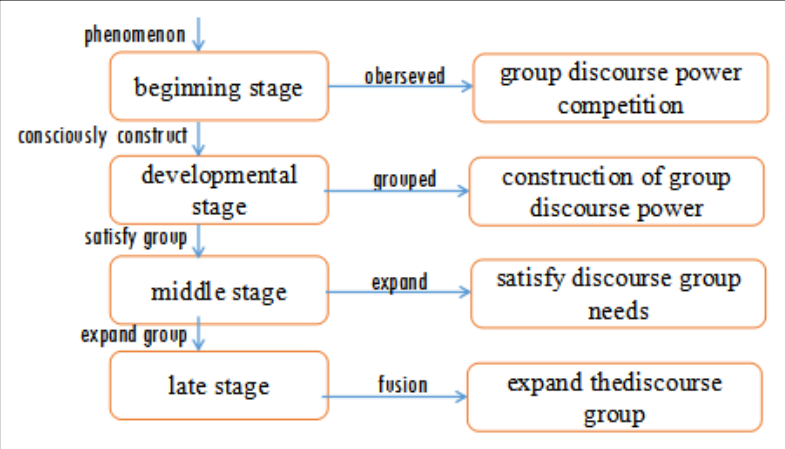

Fig. 4. Four stages in utilizing the discourse power

The charm of discourse power lies in the agitation and demagoguery. It exists in the form of groups, takes advantage of group psychology, and is perfectly applied in the commercial field. Discourse power marketing is now closely associated with business model, and also believed to be the future trend.

\section{ACKNOWLEDGMENT}

J. Xu thanks Hangzhou Humanity and Social Institution and Zhejiang Business Vocational College in financing the research of this paper, and L.Zhu, Y.Wang, T.Zhang in cooperation to complete this paper.

\section{REFERENCES}

[1] M. Foucault, "The Archaeology of Knowledge", A.M.S. Smith Trans., Vintage Books, 1982.

[2] R Amit and C Zott, "Creating Value through Business Model Innovation" in Mit Sloan Management Review, 2012, vol.53 (3), pp :41-49.

[3] M. Pynnönen, J.Hallikas and P. Ritala "Managing Customer-Driven Business Model" in International Journal of Innovation Management, 2012, vol.16 (04) .

[4] G. Le Bon. "The Crowd: A Study of the Popular Mind", Cherokee Publishing Company, Atlanta, GA 1982; 2nd edition, September 1982.

[5] J. Van Ginneken. "Crowds, psychology, and politics, 1871-1899." Cambridge, England, UK: Cambridge University Press, 1992. pp. 130131.

[6] IResearch Institution, "2017 China Local Living O2O Industry Research Report", Beijing, July 11, 2017. (In Chinese) 